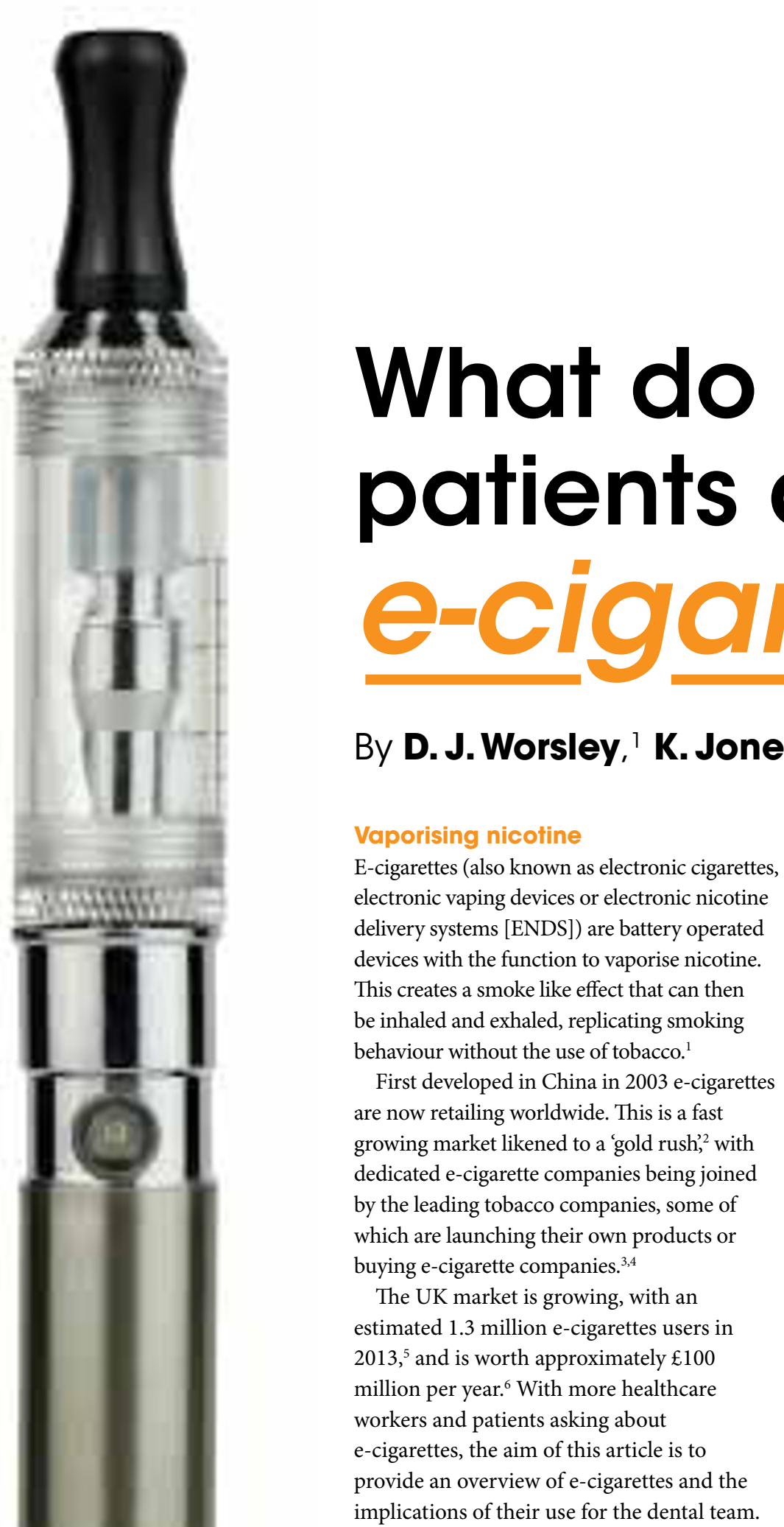

ARTICLE

\title{
What do we tell patients about
}

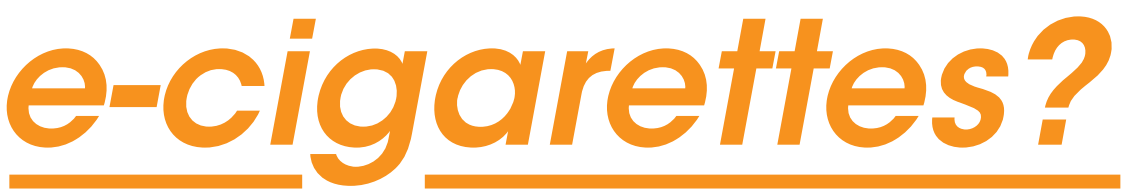

\section{By D. J. Worsley, ${ }^{1}$ K. Jones ${ }^{2}$ and Z. Marshman ${ }^{3}$}

\section{Vaporising nicotine}

-cigarettes (also known as electronic cigarettes, This creates a smoke like effect that can then inhaled and exhaled, replicating smoking the use of tobacco.

e-cigarettes which are launching their own products or e-cigarette companies.

The UK market is growing, with an estimated 1.3 million e-cigarettes users in $013,{ }^{5}$ and is worth approximately $£ 100$ implications of their use for the dental team.

\section{What are e-cigarettes?}

E-cigarettes comprise three main components: a battery, a cartridge and an atomiser, which is an electronic heating element for vaporisation of the liquid. The basic types of e-cigarettes include the disposable e-cigarette, a rechargeable e-cigarette with replaceable cartridges prefilled with liquid, and a rechargeable e-cigarette with a liquid refillable cartridge/tank (Fig. 1).
The cartridge contains a liquid known as e-liquid, e-juice, or smoke-juice. The ingredients may contain nicotine, flavourings, water, citric acid as well as either propylene glycol and/or glycerol. The nicotine concentration depends on the brand and the product, ranging from $0 \mathrm{mg} / \mathrm{ml}$ to $24 \mathrm{mg}$ / $\mathrm{ml}$ and may be labelled as nicotine-free, or referred to as mild/low, regular/medium or strong/high. In addition e-liquids with $36 \mathrm{mg} /$ $\mathrm{ml}$ to $50 \mathrm{mg} / \mathrm{ml}$ of nicotine are available.

A wide range of natural and/or artificial flavours may be incorporated into the nicotine or nicotine-free versions, for example, traditional tobacco flavours, fruit, chocolate and various novelty flavours such as candy floss and margarita.

The replaceable cartridges for e-cigarettes are preloaded with e-liquid, and bottles of 10 , 30 or $50 \mathrm{ml}$ of e-liquid are available for the liquid refillable e-cigarettes.

Depending on the e-cigarette device, activation of vaporisation of the e-liquid may occur when 'drawing' on the device, or by use of a switch, which activates the atomiser to vaporise liquid that can then be drawn into the lungs. This process may be termed either 'vaping' or 'smoking. In this article the use of an e-cigarette will be termed vaping, and the use of a tobacco cigarette termed smoking.

In contrast to a tobacco cigarette, which may provide between 10 to 20 puffs per cigarette and has a natural endpoint, the number of puffs from an e-cigarette depends 

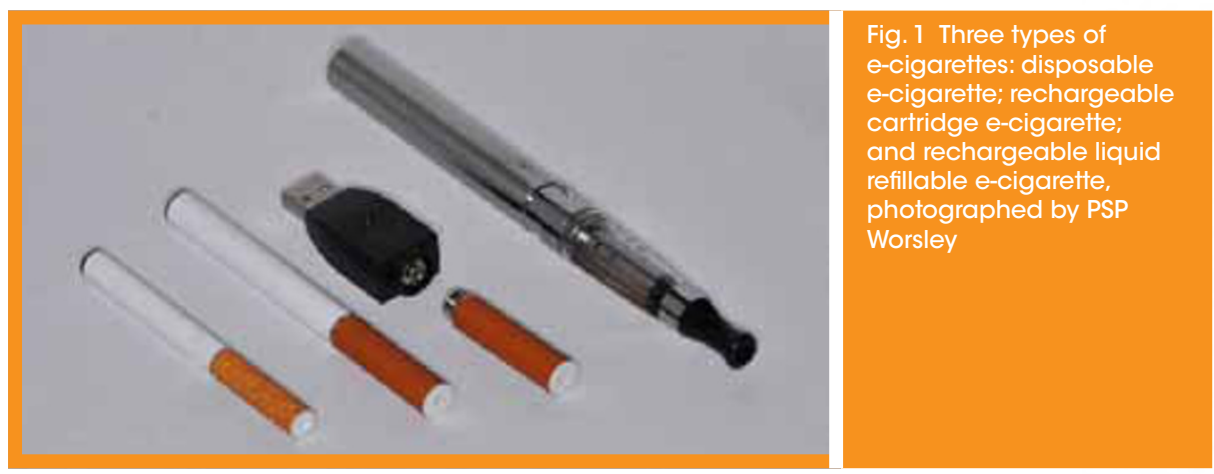

on brand, product and the way it is used. The range for disposable and replaceable cartridges is reported to be from 150 puffs to 300 puffs, where 300 puffs is equivalent to 40 cigarettes $^{7}$ and a $10 \mathrm{ml}$ bottle of e-liquid used in refillable e-cigarettes is equivalent to 200 cigarettes. ${ }^{8}$ E-cigarettes are available to buy on the Internet, at dedicated e-cigarette shops, in the supermarkets and other retail shops, and at street vendors.

\section{Who uses e-cigarettes and why?} E-cigarettes are relatively new on the UK market. Their use is mainly among tobacco smokers, which in England is 19.6\% of the population. ${ }^{9}$

The results of the Smoking Toolkit Study (STS) on e-cigarettes in England showed that the 'current use' (people who are using e-cigarettes at the time of the survey) has steadily increased among smokers, rising from $2 \%$ in 2011 to $15 \%$ in $2013 .{ }^{9}$ The Action on Smoking and Health (ASH) survey on e-cigarettes found that current use among ex-smokers had increased from 1\% in 2011 to $3 \%$ in 2012; among adults who had never smoked current users were $0 \%$; current use among children aged 11 to 18 was rare and there was little use reported among children who had or who currently smoked. ${ }^{10}$

In the ASH survey $24 \%$ of smokers and 5\% of ex-smokers had 'tried' e-cigarettes (people who had tried but no longer used e-cigarettes). Among adults who had never smoked $1 \%$ had tried them and among children who had never smoked $1 \%$ had tried them. ${ }^{10}$

While the use of electronic cigarettes in children is low in the UK, the results of surveys from the United States have revealed an increasing trend in the use of e-cigarettes among children. ${ }^{11}$

E-cigarettes are claimed to be cheaper than tobacco cigarettes. A price comparison by one company estimated the cost of using e-cigarettes to be $80 \%$ cheaper than smoking tobacco cigarettes. ${ }^{12}$ The estimated cost for an e-cigarette, equivalent to 20 tobacco cigarettes, is less than $£ 2^{13}$ compared to the average cost of about $£ 7$ for 20 tobacco cigarettes; the $20 \%$ tax on e-cigarettes is lower than the $80 \%$ tax on tobacco cigarettes. ${ }^{14}$ Users of e-cigarettes give a range of reasons for vaping, some of which are listed in Table 1.

\section{What is the current legislation and} regulation of e-cigarettes in the UK? In the UK, e-cigarettes are regulated as general consumer products and have to meet the General Products Safety Regulations 2005, the Chemical (Hazard Information and Packaging for Supply) regulations 2009, and are monitored by Trading Standards. ${ }^{1}$ They are not subject to the stricter medicines regulations unless they claim or imply that they can assist in giving up smoking ${ }^{16}$ and at present no e-cigarettes are regulated as medical products.

The advertising of e-cigarettes is becoming reminiscent of the tobacco cigarette advertising of the past: glamorous, desirable, sexy, and fashionable, with marketing being directed at both smokers and non-smokers. ${ }^{2}$ Adverts for e-cigarettes are subject to few restrictions at present. The e-cigarette may not be shown in television advertisements but can be shown on posters, on the Internet etc. Advertisements for e-cigarettes cannot claim or imply that they are a smoking cessation tool, a harm reduction tool, harmless or risk-free unless there is evidence to support the claims. ${ }^{17}$ Despite these restrictions, a recent report found that e-cigarettes were being promoted as 'a healthier and safer source of nicotine' and 'good for cutting down, quitting or switching from traditional cigarettes.' In 2014 the Committee of Advertising Practice (CAP) launched a public consultation to develop clear advertising rules for the e-cigarette industry. ${ }^{18}$

E-cigarettes are not subject to tobacco control measures and therefore they may be vaped in public spaces unless organisations have imposed restrictions on their use.

In March 2014 an Act was passed allowing for regulations to prohibit the sale of nicotine products, including e-cigarettes, to under 18-year-olds in England. ${ }^{19}$ The Welsh Government are considering a similar ban. ${ }^{20}$ Some e-cigarette manufacturers and
Table 1 Reasons given for use of e-cigarettes ${ }^{1,9,10}$

For recreational purposes

As preferable to smoking tobacco cigarettes

As an alternative to tobacco cigarettes where smoking is prohibited

To reduce exposure of others to second hand smoke

As a cheaper alternative to tobacco

As a harm reduction tool to help reduce the quantity of tobacco being smoked

As a smoke cessation tool to help reduce and quit tobacco

retailers have put in place self-imposed sales restrictions to those aged 18 years and older.

\section{What is the proposed legislation and regulation of e-cigarettes in the UK?}

In June 2013, following consultations and research into e-cigarettes by the Medicine and Healthcare Regulatory Agency (MHRA), an announcement was made that the UK Government had 'decided that the MHRA will regulate all nicotine containing products (NCPs) as medicines so that people using these products have the confidence that they are safe, are of the right quality and work. ${ }^{21}$ Public Health England is in favour of the regulation of all NCPs, including e-cigarettes as medicines. ${ }^{22}$ These pronouncements concurred with the proposal from the European Commission to the European Parliament that in the revised version of the 2001 Tobacco Products Directive (TPD) e-cigarettes should be regulated as medicines. However, in February 2014 the European Parliament approved a revised EU Tobacco Products Directive (TPD). ${ }^{24}$ The TPD makes a distinction between e-cigarettes that make medicinal claims such as aiding smoking cessation, and e-cigarettes that don't, referred to as 'consumer cigarettes' in the TPD. E-cigarettes that make medicinal claims will be regulated under medicines regulation and 'consumer e-cigarettes' will need to meet the TPD regulations listed below:

> Nicotine containing liquids placed on the market should not exceed $20 \mathrm{mg} / \mathrm{ml}$

$>$ E-cigarettes placed on the market should deliver a consistent nicotine dose

$>$ E-cigarette products must be child and tamperproof

$>$ E-cigarettes must meet certain safety and quality requirements

> E-cigarette packaging must include health warnings, information on addictiveness and toxicity and a list of all the ingredients. 
In addition there is to be monitoring of the market for evidence of e-cigarettes leading to nicotine addiction or acting as a gateway to tobacco consumption. It will be up to each Member State to decide on age limits, regulation of flavouring and rules on 'vape' free environments. ${ }^{24,25}$ The decision by the European Parliament not to regulate all e-cigarettes as medical products 'has raised some uncertainty about the MHRA licensing plans.' The MHRA will continue to advise e-cigarette companies to licence their products. ${ }^{23}$

\section{What evidence is there about the safety, quality and efficacy of e-cigarettes?}

There is increasing research into e-cigarettes but at present the evidence base for their safety, quality and efficacy is not extensive. In 2013, the World Health Organisation $(\mathrm{WHO})^{26}$ stated: 'the safety of ENDS has not been scientifically demonstrated' and 'the potential risks they pose for the health of users remain undetermined. This concurs with the findings of the MHRA, which recently completed market and scientific research of NCPs including e-cigarettes. They concluded that, 'although there is no evidence to suggest that using electronic cigarettes is more harmful than smoking tobacco cigarettes there remains a paucity of scientific evidence on the long-term effects. ${ }^{16}$

In addition to the undetermined long-term safety concerns of the effect of e-cigarettes on health, variations have been found in the quality of the e-cigarette products in relation to the ingredients of the e-liquids, which could vary in nicotine concentration within the same batch; could contain additional additives and contaminants; and could vary in the effectiveness of nicotine delivery from devices. ${ }^{16}$ Concern was raised at a recent European Commission ${ }^{27}$ meeting by two e-cigarette associations that 'there were still quality and safety issues with some products and that not all producers of electronic cigarettes were 'responsible' manufacturers'.

Although the safety of e-liquids for both short-term and long-term health requires further research, $\mathrm{ASH}^{5}$ has stated that 'they are likely to be a safer alternative to smoking. In a study of 20 tobacco cigarette smokers who substituted tobacco cigarettes with e-cigarettes for two weeks all the tobacco smoke toxins tested for were substantially reduced. ${ }^{28} \mathrm{~A}$ study on vapour produced from 12 brands of e-cigarettes, which analysed toxicants normally found in tobacco cigarette smoke, found that the toxicants (some of which were carcinogenic) examined for were present, but at a ratio of 9 to 450 times less than in tobacco smoke. ${ }^{29}$ Another study found that exhaled vapour produced from three models of e-cigarettes contained nicotine and that people in close proximity would be exposed to the nicotine but it would be at levels ten times lower than nicotine from tobacco cigarette smoke. ${ }^{30}$

While the use of 'e-cigarettes may be useful in reducing the harm of cigarette smoking in those unable to quit ${ }^{28}$ it 'may involuntarily expose non-users to nicotine. ${ }^{30}$

Nicotine is an addictive substance and can be toxic, however, studies on NRT have not found nicotine to be implicated in cardiovascular disease ${ }^{31}$ or in cancer. ${ }^{32}$ While tobacco is known to be harmful to periodontal health, ${ }^{33}$ nicotine itself may be implicated in adverse effects on the periodontium through various mechanisms such as peripheral vasoconstriction. ${ }^{34}$

\section{The efficacy of e-cigarettes in smoking cessation}

Quitting smoking by stopping abruptly or by gradual reduction with or without aids such as nicotine replacement therapy (NRT) and/or support ${ }^{35}$ has, until the 2013 National Institute for Care and Health Excellence (NICE) guidance on tobacco harm reduction, ${ }^{36}$ been the main approach to reducing tobacco consumption.

The STS 9 showed that the percentage of smokers attempting to stop smoking in 2013 ranged from $29-36 \%$ and smokers trying to quit who used support in the form of smoking cessation services, over the counter NRT or medical prescriptions were increasingly using e-cigarettes to support their quit attempt. The efficacy of e-cigarettes as a smoking cessation tool has yet to be scientifically demonstrated ${ }^{26}$ but anecdotal findings from newspaper articles ${ }^{15}$ and comments from online newspaper threads indicate that some users are reporting that use of e-cigarettes has enabled them to quit smoking tobacco.

A recent randomised control study by Bullen et al. ${ }^{37}$ investigating quit rates using e-cigarettes and nicotine patches over a six month period found that there was no statistically significant difference between the quit rate in the group using e-cigarettes delivering nicotine (quit rate 7.3\%), compared with the group using nicotine patches (quit rate 5.8\%). An additional finding from the study was that, at six months, $57 \%$ of those in the e-cigarette delivering nicotine group had reduced their tobacco consumption by half or more.

\section{The efficacy of e-cigarettes in harm reduction}

Harm reduction may be defined as 'the long-term use by smokers of less harmful non-tobacco products, with or without a quit attempt. ${ }^{38}$ The recent NICE guidance on Tobacco harm reduction approaches to smoking 36 advises that a tobacco harm reduction approach may be helpful for people who:

$>$ May not be able to stop smoking (or do not want to stop) in one step

$>$ May want to stop smoking, without necessarily giving up nicotine

> May not be ready to stop smoking, but want to reduce the amount they smoke.

A broad range of harm reduction strategies are advised, including the use of NRTs, which are licensed nicotine products. E-cigarettes are not licenced as NRTs and because at present their safety, quality and efficacy cannot be assured, they are not recommended. Products on the market that are regulated as medicines, and mimic the hand to mouth action of smoking, are inhalators, for example Nicorette, NicAssist. The inhalators do not have an atomiser and the liquid nicotine concentration is $15 \mathrm{mg} / \mathrm{ml}$.

Surveys are showing that, despite e-cigarettes not being recommended as a harm reduction approach, there is an increasing use of e-cigarettes by smokers to help them reduce the amount of tobacco they smoke, ${ }^{10}$ with $10 \%$ of smokers now using them as a harm reduction measure and this has overtaken NRTs. ${ }^{9}$

\section{Evidence of e-cigarettes as a 'gateway" to tobacco use}

There are concerns that the use of e-cigarettes containing nicotine, a highly addictive psychoactive drug, may act as a 'gateway' to the use of tobacco products by those who have never smoked..$^{39,40}$ Some argue that it is preferable for those who decide they may wish to smoke to choose e-cigarettes rather than tobacco

\section{THERE IS CONCERN THAT THE USE OF}


cigarettes. ${ }^{41}$ At present the surveys in the UK have shown that there is little uptake of e-cigarettes by children or those who have never smoked, ${ }^{10}$ but the de Andrade et al. ${ }^{2}$ report found marketing strategies targeted two groups: the committed smoker, who may think about quitting; and the younger social smoker and non-smoker. It may be too early in this emerging market to find evidence of e-cigarettes as a 'gateway' to smoking.

\section{Evidence of vaping renormalising smoking}

Smoking was a social norm in the UK in the 1950s and 1960s, advertised widely and allowed in public places, on transport and often in the workplace. The comprehensive range of tobacco control measures introduced gradually over recent years has meant that many of those in their early twenties today have grown up without the same exposure to smoking behaviours as experienced by their parents/carers or grandparents. There is a concern that vaping, which mimics smoking behaviour and is being widely advertised and allowed anywhere (unless banned) may renormalise smoking. ${ }^{38,42}$ Distinguishing between vaping and smoking may be obvious for some but not for others, for example, children ${ }^{43}$ - it may be difficult to police and it may be too early for research to establish if, or how, vaping changes the perceptions of smoking.

\section{WHAT DO WE TELL PATIENTS? \\ Advice about e-cigarettes for patients}

Dental teams already have an important role to play in advising patients to cease tobacco consumption. A recent publication of the second edition of Smokefree and smiling ${ }^{44}$ reiterated the advice to be given to patients to aid cessation of tobacco use. At the moment e-cigarette use as a smoking cessation tool is not supported. ${ }^{22}$ However, patients may be using and asking the dental team about e-cigarettes, so what do we tell them? Based on the literature reviewed above, current advice about e-cigarettes for patients is summarised in Table 2. However, dentists and dental care professionals need to recognise the potential for changes to this advice as regulation $s^{24}$ change and findings from research on the safety and effectiveness of e-cigarettes are published.

\section{Permission or prohibition of e-cigarette use on your premises} With the lack of regulation and legislation regarding where e-cigarettes can be vaped, organisations such as train operators, chains

\section{Table 2 Advice about e-cigarettes for patients (April 2014)}

The long term safety of e-cigarettes is not yet established ${ }^{16,25,26}$

E-cigarettes are likely to be less harmful than tobacco cigarettes ${ }^{1.5}$

The effectiveness of e-cigarettes as either a smoking cessation tool or a harm reduction tool is not yet established 25,26

At present no e-cigarettes are licensed as a medicine 16,44 and patients are recommended to use licensed NRT products to quit or reduce tobacco consumption ${ }^{1,43,45}$

Advice to patients who are unable or unwilling to use licensed NRT products is that although the safety of e-cigarettes cannot be assured they are likely to be a lower risk option than continuing to smoke'

Advise patients that there is the potential for advice about e-cigarettes to change as findings from research about the safety and effectiveness of e-cigarettes is published

Advise patients that referral to the Stop Smoking Services is an option to consider

of pubs, a number of schools and work organisations have implemented their own regulations.

$\mathrm{ASH}^{43}$ has produced a comprehensive guidance sheet with five questions to ask (Table 3) before deciding whether to permit or prohibit e-cigarette use on premises.

Knowledge of current legislation and regulations as well as the safety of e-cigarettes and their potential to renormalise smoking behaviour may help inform decisions on whether to permit or prohibit use of e-cigarettes on your premises.

\section{What are the public health arguments for and against e-cigarettes?}

Statistics from Cancer Research $\mathrm{UK}^{45}$ show that tobacco consumption is the single greatest cause of preventable illness and early death with an estimated 102,000 people dying in the UK in 2009 from smoking-related-diseases including cancers. Some argue that e-cigarettes may be a potential revolution to public health ${ }^{41,46}$ because there is acceptance that they are likely to be less harmful than tobacco cigarettes, ${ }^{5}$ that e-cigarette use is predominantly by former smokers ${ }^{10}$ and studies show that their use can reduce tobacco consumption. ${ }^{37}$

While some suggest that is it preferable that adolescents try e-cigarettes rather than tobacco cigarettes, ${ }^{41}$ others are concerned that the marketing, combined with the lack of regulations, may lead to widespread use, a re-socialising of smoking, ${ }^{42}$ and an undermining of the prevention and cessation services. ${ }^{1}$ Whether e-cigarettes are an effective smoking cessation tool and harm reduction tool has yet to be established. Nicotine is highly addictive, and whether vaping of e-cigarettes will perpetuate nicotine use or act as a gateway to smoking is as yet unknown.

\section{CONCLUSION}

Further research is needed on the safety, quality and effectiveness of e-cigarettes
Table 3 Questions to ask when deciding to permit or prohibit e-cigarette use

What are the issues you are dealing with? What do you need to control?

Do you have concerns about the possibility of harm from NCPs?

Will restricting or prohibiting the use of NCPs support compliance with smoke-free policies?

Do you want your policy to help improve people's health?

and also on their efficacy as a smoking cessation and harm reduction tool. With the rapid expansion of this market and the availability of new and changing products, smokers, former smokers and those who have never smoked are already deciding the purpose of e-cigarettes. Delays in regulation and legislation may potentially allow the markets to determine the course of their use. Meanwhile, as health professionals, we need to be able to answer the questions raised by patients about e-cigarettes and keep abreast of this rapidly developing market.

1. British Medical Association. BMA calls for stronger regulation of e-cigarettes. London: BMA, 2013. Online article available at http:// bma.org.uk/-/media/Files/PDFs/Working\%20 for\%20change/Improving\%20health/ tobaccoecigarettespublicplaces_jan2013.pdf (accessed June 2014).

2. de Andrade, M, Hastings, G, Angus, K, Dixon, D, Purves R. The marketing of electronic cigarettes in the UK. Cancer Research UK, 2013. Online report available at https://www. cancerresearchuk.org/sites/default/files/cruk marketing_of_electronic_cigs_nov_2013.pdf (accessed June 2014).

3. Esterl M. Big Tobacco begins takeover of the e-cigarette market. Wall Street Journal, 2013. Online article available at http://blogs.wsj.com/ corporate-intelligence/2013/11/18/big-tobaccobegins-its-takeover-of-the-e-cigarette-market/ (accessed June 2014).

4. Titcomb J. BAT plans to dominate e-cigarette market. London: The Telegraph, 2013. Online article available at http://www.telegraph.co.uk/ finance/newsbysector/epic/bats/10213091/ 
BAT-plans-to-dominate-e-cigarette-market. html (accessed June 2013).

5. Action on Smoking and Health. Electronic cigarettes (also known as vapourisers). ASH, 2014. Online article available at http://ash.org.uk/files/ documents/ASH_715.pdf (accessed June 2014).

6. Clancy R. Imperial Tobacco to launch e-cigarette next year. London: The Telegraph, 2013. Online article available at http://www.telegraph.co.uk/ finance/newsbysector/retailandconsumer/ leisure/10244981/Imperial-Tobacco-to-launche-cigarette-next-year.html (accessed June 2014).

7. VIP Electronic-Cigarette. How long do cartomisers last? VIP, 2014. Online information available at http://www.vipelectroniccigarette. co.uk/how-long-cartomizer-last.html (accessed June 2014).

8. VIP Electronic-Cigarette. $10 \mathrm{ml}$ E-liquid range. VIP, 2014. Online information available at http://www.vipelectroniccigarette.co.uk/10mle-liquid-c-34_37.html (accessed June 2014).

9. Smoking Toolkit Study (STS). Latest trends in smoking in England from the Smoking Toolkit Study. STS, 2013. Online information available at www.smokinginengland.info/latest-statistics/ (accessed June 2014).

10. Action on Smoking and Health. Use of e-cigarettes in Great Britain among adults and young people. ASH, 2014. Online article available at www.ash.org.uk/files/documents/ ASH_891.pdf (accessed June 2014).

11. Corey, C, Wang, B, Johnson S.E, Apelberg, $\mathrm{B}$, Husten C. Electronic cigarette use among middle and high school students - United States, 2011-2012. Morbidity and Mortality Weekly Report 2013; 62: 729-730.

12. VIP Electronic-Cigarette. Electronic cigarette vs tobacco cigarettes price comparison. VIP, 2012 Online comparison available at http://www. vipelectroniccigarette.co.uk/price-comparison. html (accessed June 2014).

13. Electronic Cigarette World. Electronic Cigarette World Buyer's Guide. Pamphlet. Electronic Cigarette World, 2013. Available in store.

14. World Health Organization. WHO report on the global tobacco epidemic 2013. Country profile: United Kingdom of Great Britain and Northern Ireland. Geneva: WHO, 2013 Online report available at http://www.who.int/tobacco/ surveillance/policy/country_profile/gbr.pdf (accessed June 2014).

15. Ranfanelli S. Why I vape. London. p 24a. The Guardian, 4 January 2014.

16. Medicines and Healthcare Products Regulatory Authority, Working Group on Nicotine Containing Products. Quality, safety and efficacy of unlicensed NCPs. MHRA, 2013. Online article available at http://www.mhra.gov.uk/home/ groups/comms-ic/documents/websiteresources/ con286839.pdf (accessed June 2014).

17. Committee of Advertising Practice. Electronic cigarettes. CAP, 2013. Online article available at http://www.cap.org.uk/Advice-Trainingon-the-rules/Advice-Online-Database/
Electronic-cigarettes.aspx (accessed June 2014).

18. Committee of Advertising Practice. CAP and $B C A P$ propose new rules for electronic cigarette advertising. CAP, 2013. Online article available at http://www.cap.org.uk/News-reports/ Media-Centre/2013/CAP-and-BCAP-proposenew-rules-for-electronic-cigarette-advertising aspx (accessed June 2014).

19. Children and Families Act 2014, c 6, Part 5, Section 92. London: HMSO, 2014.

20. BBC. E-cigarettes to be stubbed out for under 18s. BBC, 2014. Online article available at http://www.bbc.co.uk/news/uk-25900542 (accessed June 2014)

21. Medicines and Healthcare Products Regulatory Authority. UK moves towards safe and effective electronic cigarettes and other nicotinecontaining products. MHRA, 2013. Online press release available at http://www.mhra.gov.uk/ home/groups/comms-po/documents/news/ con286856.pdf (accessed June 2014).

22. Public Health England. Electronic cigarettes: PHE position and Q\&A. PHE, 2013.

23. Medicines and Healthcare Products Regulatory Authority. European Parliament vote on nicotine containing products. MHRA, 2013. Online article available at http://www.mhra.gov.uk/ NewsCentre/CON322753 (accessed June 2014).

24. European Parliament. Revised tobacco products directive on 26 February 2014. Brussels: European Parliament, 2014. Online information available at http://ec.europa.eu/ health/tobacco/products/revision/index en.htm (accessed June 2014).

25. European Commission. Questions \& answers: new rules for tobacco products. European Commission, 2014. Online press release available at http://europa.eu/rapid/press-release_ MEMO-14-134_en.htm (accessed June 2014).

26. World Health Organization. Electronic cigarettes (e-cigarettes) or electronic nicotine delivery systems. Geneva: WHO, 2013. Online article available at http://www.who.int/tobacco/ communications/statements/eletronic cigarettes/en/ (accessed June 2014).

27. European Commission. Minutes of meeting 22 November 2013. European Commission, 2013. Online minutes available at http://ec.europa.eu/ health/tobacco/docs/ev_20131122_mi_en.pdf (accessed June 2014)

28. Goniewicz M L. E-cigarettes: a review of their efficacy and potential for harm reduction. Presentation given by Dr Maciej Goniewicz, Queen Mary University of London, at an APPG meeting on harm reduction, 2013. Online presentation available at http://www.ash.org uk/files/documents/ASH_858.pdf (accessed June 2014).

29. Goniewicz M L, Knysak, J, Gawron, M et al. Levels of selected carcinogens and toxicants in vapour from electronic cigarettes. Tob Control 2013; 23: 133-139.

30. Czogala, J, Goniewicz M L, Fidelus, B, ZielinskaDanch, W, Travers M J, Sobczak A. Secondhand exposure to vapours from electronic cigarettes. Nictoine Tob Res 2013; 16: 655-662.

31. Benowitz N L, Hanson, A, Jacob P 3rd Cardiovascular effects of nasal and transderma nicotine and cigarette smoking. Hypertension 2002; 39: 1107-1112.

32. Murray R P, Connett J E, Zapawa L M. Does nicotine replacement therapy cause cancer? Evidence form the Lung Health Study. Nicotine Tob Res 2009; 11: 1076-1082.

33. Nunn M E. Understanding the etiology of periodontitis: an overview of periodontal risk factors. Periodontol 2000 2003; 32: 11-23.

34. Genco R J, Borgnakke W S. Risk factors for periodontal disease. Periodontol 2000 2013; 62: 59-94.

35. National Institute for Health and Care Excellence. Brief interventions and referral for smoking cessation (PH1). NICE, 2006. Online guidance available at http://guidance.nice.org uk/PH1 (accessed June 2014).

36. National Institute for Health and Care Excellence. Tobacco: harm reduction approaches to smoking. NICE, 2013. Online guidance available at http://publications.nice.org.uk/ tobacco-harm-reduction-approaches-tosmoking-ph45 (accessed June 2014)

37. Bullen C, Howe C, Laugesen $\mathrm{M}$ et al. Electronic cigarettes for smoking cessation: a randomised controlled trial. Lancet 2013; 382: 1629-1637.

38. de Andrade, M, Hastings G. Tobacco harm reduction and nicotine containing products. Research priorities and policy directions. Cancer Research UK, 2013. Online article available at http://www.cancerresearchuk.org/sites/default/ files/tobacco-harm-reduction.pdf (accessed June 2014).

39. Grana R A. Electronic cigarettes: a new nicotine gateway? J Adolesc Health 2013; 52: 135-136.

40. Pepper J K, McRee A L, Gilkey M B. Healthcare providers' beliefs and attitudes about electronic cigarettes and preventive counselling for adolescent patients. J Adolesc Health 2014; 54: 678-683.

41. Etter J F. Should electronic cigarettes be as freely available as tobacco cigarettes? Yes. BMJ 2013; 346: f3845.

42. Chapman S. Should electronic cigarettes be as freely available as tobacco cigarettes? No. BMJ 2013; 346: f3840.

43. Action on Smoking and Health. Will you permit or prohibit e-cigarette use on your premises? $\mathrm{ASH}, 2014$. Online article available at www.ash org.uk/files/documents/ASH_900.pdf (accessed June 2014).

44. Public Health England. Smokefree and smiling. Helping dental patients to quit tobacco. 2nd ed. Public Health England, 2014. Online guidance available at https://www.gov.uk/government/ publications/smokefree-and-smiling (accessed June 2014).

45. Cancer Research UK. Smoking statistics. Cancer Research UK, 2013.

46. Hajek P. MHRA regulation of electronic cigarettes. The Smokers Clinic Blogspot, 2013. Online blog available at http://thesmokersclinic.blogspot. co.uk/2013/06/mhra-regulation-of-electroniccigarettes.html (accessed June 2014) 